\title{
More needed to reduce radon-related cancer
}

$\mathrm{M}$ ore than 35 years after studies first linked radon to lung cancer, researchers and public health officials are urging new legislation to prevent an estimated 3000 Canadians from dying every year after exposure to the radioactive gas.

Radon is the second-leading cause of lung cancer, after smoking, accounting for about $16 \%$ of lung cancer deaths annually, reports the Canadian Cancer Society.

Radon is a naturally occurring byproduct of uranium that can seep into any building from the soil. Radon cannot be seen, tasted or smelled. The carcinogen may accumulate in any home - regardless of a region's geographic risk - particularly in basements and crawl spaces that have not been properly ventilated.

"About $46 \%$ of the country, geographically, has the potential to be at high risk of radon exposure," says Rob Nuttall, assistant director, Cancer Control Policy for the Canadian Cancer Society. Portions of Saskatchewan, Manitoba, New Brunswick and the Yukon are at high risk because of their geology, but radon can be present anywhere in Canada, and parts of British Columbia and Ontario also have high levels, experts say.

Current Health Canada guidelines recommend that whenever the average annual concentration of radon exceeds $200 \mathrm{~Bq} / \mathrm{m}^{3}$, the owner of that dwelling should take remedial action. That guideline is double the World Health Organization's recommendation of $100 \mathrm{~Bq} / \mathrm{m}^{3}$.

The federal guidelines are voluntary, and provincial/territorial building codes have taken a piecemeal approach to adopting them, leaving regulatory gaps, says Anne-Marie Nicol, an assistant professor at Simon Fraser University's Faculty of Health Sciences. Nicol, who specializes in communicating environmental exposures that affect health, says real estate transactions, workplace health and safety laws, and daycare licensing are just a few of the regulatory arenas where provinces, territories and municipalities could compel radon testing and remediation.

Knowing the level of radon requires testing, either through the use of in-home

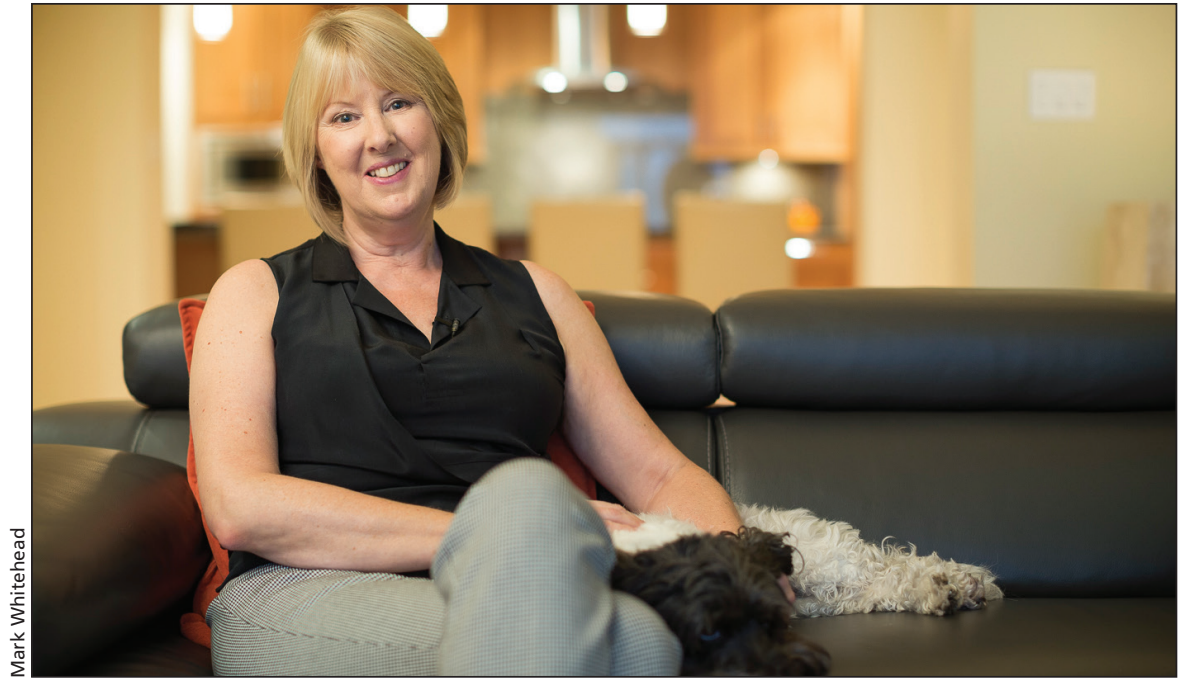

Janet Whitehead, a nonsmoker with lung cancer, discovered her former Ottawa home had 16 times the recommended limit of radon.

kits or by companies that can also provide remediation. Public awareness campaigns, though, have been unsuccessful at motivating people not only to test, but fix the problem, says Dr. Ray Copes, chief, environmental and occupational health for Public Health Ontario.

"Guidelines by themselves do nothing. The real key here is action."

Copes questions the effectiveness of merely exhorting people to take corrective action if the radon in their homes or offices is above a number. He points to a survey the Canadian Cancer Society released in November 2014. Among the 1238 Canadians surveyed, only $4 \%$ had had their homes tested for radon, and only $15 \%$ knew that radon is the secondleading cause of lung cancer. (The online survey has a margin of error of plus or minus 2.8\%, 19 times out of 20.)

"What we really have to look at is why we have not made greater progress on reducing radon exposure for Canadians and do we need to look at other strategies such as building code requirements and implementing those," says Copes.

Janet Whitehead is one of the few Canadians who is aware of how much radon was present in at least one home she owned - but only because she sought answers after a startling diagnosis. A nonsmoker, Whitehead was shocked to learn in early 2009 , just before her 55th birthday, that lung can- cer was causing her persistent cough and shortness of breath.

By chance, her husband Alan's company provides radon prevention and mitigation services. Although the couple had moved to Vancouver, they sent radon test kits to their previous homes in Ottawa and in Cornwall. The one in Ottawa, where they lived 19931997 , tested at $3200 \mathrm{~Bq} / \mathrm{m}^{3}-16$ times the recommended limit.

"Once we got the results from the house in Ottawa, we were able to say 'That caused my cancer,"' says Whitehead, who is now five years postsurgery and recovering well.

Two recent studies point to the potential risk homeowners face. In 2014, the BC Lung Association distributed radon test kits to more than 2000 homes in Prince George and 230 homes in and around Castlegar. On average, one in three homes in Prince George and one in two homes in Castlegar tested above the $200 \mathrm{~Bq} / \mathrm{m} 3$.

In 2012, Health Canada released the results of a two-year survey of homes across Canada indicating that $6.9 \%$ of Canadians are living in homes with radon levels above the $200 \mathrm{~Bq} / \mathrm{m} 3$ guideline. The only way to know the level in a particular house is to test, Health Canada emphasizes. - Laura Eggertson, Ottawa, Ont.

CMAJ 2015. DOI:10.1503/cmaj.109-5016 